\title{
HET NIEUWE ZOOLOGISCH INSTITUUT DER UNIVERSITEIT VAN AMSTERDAM
}

DOOR

\author{
Prof. Dr. C. PH. SLUITER.
}

(Met Plaat X).

Nu de plaats, waar WEBER gedurende bijna veertig jaren gewerkt heeft voor het onderwijs in de Zoologie, op het punt staat verlaten te worden en bij het verschijnen van dezen Feestbundel zeker als laboratorium en gehoorzaal verlaten en de Zoologie in het nieuwe laboratorium gehuisvest is, gaan onwillekeurig onze gedachten terug naar de jaren, die in het oude laboratorium zijn doorgebracht. Hoe aanlokkelijk ook een dergelijke terugblik voor ons, ouderen van dagen, moge zijn, zoo ligt het toch geenszins in mijne bedoeling een historisch beeld te geven van wat er in dien tijd in het laboratorium gewerkt is. Slechts zij er aan herinnerd, dat van 1883 af WEBER eerst als buitengewoon hoogleeraar, maar spoedig daarop als gewoon hoogleeraar de Zoologie en Vergelijkende Anatomie te Amsterdam had te doceeren en de leiding van het laboratorium op hem rustte.

Gedurende de eerste jaren stond Dr. C. KERBERT hem als lector ter zijde, sedert 1890 de schrijver van deze regelen. In 1898 waren de plannen voor de "Siboga Expeditie” tot werkelijkheid geworden en in September 1898 nam WEBER zijn ontslag als gewoon hoogleeraar, maar bleef aan de Universiteit verbonden als buitengewoon hoogleeraar, terwijl aan hem tevens het beheer van de vereenigde zoologische verzamelingen van de Gemeente en van het Kon. Zoolog. Genootschap „Natura Artis Magistra" werd opgedragen. Als gewoon hoogleeraar en directeur van het laboratorium volgde schrijver hem toen op.

De herinneringen aan het werk in het oude laboratorium verricht behooren voor WEBER en mij zeker tot de aangenaamste van ons leven. De meesten van onze toenmalige studenten zijn nu mannen en vrouwen in een zelfstandige positie, velen met een goeden naam in de wetenschappelijke wereld; verscheidene zijn onze tegenwoordige ambtgenooten en vrienden. Het oude laboratorium met zijn gehoorzaal heeft aan zijn roeping beantwoord, al was de geheele inrichting een uiterst gebrekkige en moest er met de ruimte gewoekerd worden. Alleen de gehoorzaal kon aan de te stellen eischen voldoen. De halfcirkelvormige gang, die om de gehoorzaal heen loopt, deed dienst als laboratorium, terwijl de uiterste hoeken van dien gang als hokjes waren afgeschoten en den wijdschen titel voerden van kamer van den hoogleeraar en van den assistent. In de beneden localiteiten was de onderwijscollectie en de werkplaats van den amanuensis ondergebracht.

Toen in vroegere jaren het aantal studenten in de biologie nog gering was en ook alleen die medische studenten, die het academisch propaedeutisch examen aflegden, den zoologischen cursus moesten volgen, kon ten minste nog aan ieder een eenigermate behoorlijke plaats gegeven worden. $\mathrm{Ja}$, zien wij op de resultaten, dan zou men tot het besluit kunnen komen, dat ten minste voor de beoefening der zoologie, kostbare inrichtingen zeker zeer aangenaam, maar niet volstrekt noodzakelijk zijn. Evenwel in de laatste 10 à 12 jaren is het aantal der studeerenden in de biologie zoozeer toegenomen, dat het de grootste moeite kostte aan ieder een bescheiden plaatsje in te ruimen. Slechts met inschikkelijkheid van beide kanten, van hoogleeraar en așsistenten eenerzijds en van de studenten 
anderzijds was het mogelijk het laboratoriumwerk behoorlijk te laten doorgaan. Maar ook het aantal medische studenten, die den zoologischen cursus volgden nam zeer sterk toe, toen door de zoogenaamde "wet LimBURG c. s.", ook aan hen, die het eindexamen der H. B. school met 5 j. c. met goed gevolg hadden afgelegd, de toegang tot de academische examens geopend werd. Meer en meer werd dan ook de toestand in het oude laboratorium onhoudbaar en werd dan ook reeds voor ongeveer 10 jaren door Burgemeester en Wethouders en door Curatoren der Universiteit de onhoudbaarheid hiervan ingezien en toegegeven, dat een aanmerkelijke vergrooting van het laboratorium volstrekt noodzakelijk was.

Deze zaak toen met WEBER besprekende, bleek het, dat een oplossing mogelijk kon zijn, en wel in verband met plannen, die hij reeds lang koesterde voor de stichting van een nieuw Zoologisch Museum op de terreinen van "Artis". De rijke schatten, die in verschillende gebouwen van het Genootschap N. A. M. verspreid zijn en het omvangrijke materiaal, dat WEBER zelf op zijn verschillende reizen naar het Noorden, naar Zuid-Afrika en naar onzen Oost-Indischen Archipel en vooral door de bekende Siboga-expeditie bijeengebracht had, zouden dan in één gebouw worden ondergebracht. De bouw van het te stichten Museum was geprojecteerd op het terrein van het Genootschap in aansluiting van het Aquariumgebouw, waarin zich ook het oude zoologisch laboratorium bevond. Dit laatste werd dan tot verbinding van de tegenwoordige museumruimten en het nieuwe Museum.

Wat evenwel van meer direct belang was voor den bouw van een nieuw zoologisch laboratorium, was, dat de ethnografische verzameling, die zich in het gebouw „De Volharding” van het Genootschap bevond, werd overgedragen aan de vereeniging „Het Koloniaal Instituut”, waardoor de geheele bovenbouw van dit gebouw vrij kwam. Het Genootschap N. A. M. was bereid dit gedeelte van het gebouw af te staan voor de inrichting van het zoologisch laboratorium, waartoe echter belangrijke verbouwingen noodig waren.

Voor de stichting van het nieuwe Museum waren reeds groote bijdragen toegezegd en ook Burgemeester en Wethouders waren bereid hun krachtigen steun te verleenen, zoodat de vooruitzichten tot het tot stand komen van het Zoologisch Museum en van het Zoologisch laboratorium zeer gunstig waren. Zoo stonden de plannen, toen de rampzalige wereldoorlog ook voor deze zaak noodlottig moest worden. Voorloopig moest van den bouw en inrichting van het Museum geheel worden afgezien. De finantieele offers, daarvoor noodig, waren in de moeilijke tijden te hoog en al blijven wij hopen, dat toch nog eenmaal op de terreinen van Artis het bedoelde Museum, waarvoor de plannen gedeeltelijk klaar liggen, moge verrijzen, onze zeventigjarige jubilaris van heden, de ontwerper van het geheele plan, geeft de hoop op, zelf nog de verwezenlijking er van te beleven. Misschien is dit te somber ingezien. Er zijn jonge krachten, die met energie en enthousiasme WeBER's werk in Amsterdam hebben overgenomen en die, al is er ook in de eerste jaren niet aan te denken; toch de plannen niet zullen loslaten. Moge het WEBER gegeven zijn toch nog eenmaal het Museumgebouw in Artis te zien verrijzen! Maar ook de inrichting van het nieuwe laboratorium ondervond door de ongelukkige oorlogsjaren, aanmerkelijke vertraging en moesten wij ons nog jaren lang in de enge ruimten behelpen. Ten slotte is het dan toch tot stand gekomen en kon tegen het einde van het jaar 1922 het gebouw in gebruik genomen worden.

De bijgevoegde plaat geeft een overzicht van de gevels, die aan beide lengtezijden van het 77 Meter lange gebouw ongeveer gelijk zijn, terwijl daaronder de plattegronden der beide verdiepingen zijn weergegeven. De bovenbouw van het gebouw. „De Volharding” heeft de heer J. OUËNDAG, architect van het Genootschap op zeer praktische wijze weten om te vormen tot een ruim en goed ingericht laboratorium. In de eerste plaats bleek het noodig de fundeering van het gebouw te versterken, daar er heel wat meer belasting moest gedragen worden. Op de hoogte van de vroegere galerij werd een nieuwe doorloopende vloer gelegd, zoodat met uitzondering van het in het midden van het gebouw gelegen Auditorium, over de geheele lengte twee verdiepingen verkregen werden. Door het aanbrengen van een groot aantal nieuwe vensters is overal voor voldoende licht gezorgd; terwijl op de tweede verdieping bovendien nog bovenlicht is. Het auditorium deelt het geheele gebouw in twee vleugels, één naar de Doklaan gekeerd en één naar den tuin van „Artis”. Deze laatste vleugel is meer bijzonder geheel voor het onderwijs ingericht, bevat op de eerste verdieping het ruime laboratorium voor de oudere studenten in de plant- en dierkunde, de kamers voor den hoogleeraar-directeur, voor den 
2 den hoogleeraar, 1 sten assistent, bibliotheek en voor de werkplaats voor den instrumentmaker-concierge.

De tweede naar de Doklaan gekeerde vleugel bevat ten eerste de woning van den concierge met vrijen toegang naar de Doklaan. Het grootste gedeelte van de eerste verdieping van dezen vleugel, een ruimte van $16 \times 10 \mathrm{M}$., is ingericht voor de opstelling van de verzameling van anatomische praeparaten en skeletten, die voor het onderwijs gebruikt worden en alleen door de "Platenkamer" van het Auditorium gescheiden is. Een behoorlijk ruime laboratoriumkamer voor physiologisch of biologische onderzoekingen sluit deze verdieping dan af.

De tweede verdieping bevat dan in den naar den tuin van het Genootschap toegekeerden vleugel, de twee groote laboratorien voor de studenten in de geneeskunde met 60 plaatsen en voor de jongere biologen met 40 plaatsen en bovendien een kamer voor den 2 en assistent. In den anderen vleugel bevindt zich een kleine collegekamer, zoogenaamde seminarium-kamer en een kleinere kamer voor speciale onderzoekingen, terwijl het grootste gedeelte van deze tweede verdieping wordt ingenomen door een even groote ruimte als die voor de onderwijsverzameling op de eerste verdieping en die bestemd is voor het verrichten van secties, het opstellen der anatomische praeparaten en voor allerlei andere doeleinden kan beschikbaar gesteld worden.

Het spreekt van zelf, dat in het bovenvermelde alleen de hoofdverdeeling van het nieuw ingerichte Zoologisch Instituut is aangegeven, maar dat er bovendien voor een donkere kamer voor photografie, voor een afzonderlijk kamertje voor microtomie enz. enz. gezorgd is, zoodat onze Amsterdamsche Universiteit met groote tevredenheid en met vertrouwen op haar nieuwe inrichting kan wijzen.

Ook met vertrouwen voor de toekomst, want er is ruimte en gelegenheid in het nieuwe laboratorium om ook in andere richting daar te werken, als tot nog toe in het oude laboratorium gebruikelijk was. Zooals in alle wetenschappen, zoo zijn er ook in onze Zoologische wetenschap in den loop der tijden bepaalde stroomingen te onderscheiden. Terwijl tot voor ruim een eeuw geleden, de beschrijving van den uitwendigen vorm der dieren en van de systematische rangschikking de hoofdzakelijke belangstelling in beslag nam, zoo weten wij hoe daarna de beoefening der vergelijkende anatomie meer en meer op den voorgrond kwam en sedert ongeveer de laatste 60 jaren in nauw verband met de vergelijkende embryologie. Sedert het in de biologische wetenschap beroemde jaar 1859, drukte de Evolutieleer haar stempel op de meeste dezer onderzoekingen. De arbeid, in dien tijd verricht, is een buitengewoon omvangrijke en men mag wel aannemen, dat in hoofdzaak deze wijze van onderzoek bereikt heeft, wat vooreerst van haar te verwachten was. Zeker, er zijn nog tal van speciale vraagstıkken, die nog onbeantwoord zijn en waarop onze vergelijkend anatomische en embryologische onderzoekingen een ten minste gedeeltelijk bevredigend antwoord zullen kunnen geven, maar in de hoofdlijnen is vooreerst wel, een zekere mate van afsluiting bereikt.

Gaan wij dan ook de publicaties der laatste decennien na, dan is een kentering in de richting van het onderzoek en dus van de tegenwoordig meer op den voorgrond tredende belangstelling niet te miskennen. Tijdschriften en handboeken, geheel gewijd aan deze nieuwere richtingen, nemen zoowel in de oude- als in de nieuwe wereld een belangrijke plaats in onze bibliotheken in en ook in de oude, wel bekende periodieken zien wij reeds deze verandering dikwijls tot uiting komen. Zoo is in de eerste plaats wel te noemen de erfelijksleer en alles wat daarmee samenhangt, ook op cytologisch gebied; dan de zoogenaamde ontwikkelingsmechanica, als deel der experimenteele zoologie; verder de biologie der dieren in engeren zin, waarbij weer de hydrobiologie een bijzondere plaats inneemt; dan de vergelijkende physiologie en eindelijk de vergelijkende dier-psychologie, die nog pas in haar eerste kinderschoenen staat. Al deze bijzondere takken van wetenschap trekken tegenwoordig meer de belangstelling en nemen ook meer de disponibele arbeidskrachten in beslag, dan 't geval is voor de vergelijkende morphologie.

De natuurkundige wetenschappen trachten nu eenmaal langs verschillende wegen de natuur zelve nader bij te komen. Niet onaardig stelt $v$. UExküLL dit voor, door de Natuur zelve met een gebouw te vergelijken, terwijl dan de wetenschap als stellage daaromheen gebouwd is, om te trachten het gebouw op verschillende plaatsen te benaderen. De stellage moet van tijd tot tijd gewijzigd en verplaatst worden en het blijkt, dat onze zoologische wetenschap in den laatsten tijd aan een dergelijke verbouwing van haar stellage behoefte heeft.

De vraag, of bij den bouw van het nieuwe laboratorium met dit alles rekening te houden was, 
was in zooverre gemakkelijk te beantwoorden, daar aan de twee meest principieele vereischten voor ieder Zoologisch onderzoek als van zelf voldaan was, daar. n.l. ten eerste het laboratorium ligt in het midden van onzen Amsterdamschen dierentuin en dan dat wij nu in onze nieuwe inrichting overvloed van ruimte hebben, die zich gemakkelijk aan de meest verschillende eischen zal laten aanpassen. De groote belangstelling en tegemoetkoming, die het laboratorium altijd van het Bestuur en wel met name van den Directeur van het Genootschap „Natura Artis Magistra”, Dr. C. KERBERT, heeft ondervonden, maakt, dat de ligging midden in den tuin met haar rijke, levende have niet alleen een schijnbaar voordeel is, maar tot nog toe ook de meest tastbare voordeelen heeft opgeleverd. En dat dit zoo blijven zal, daarvoor staat ons borg het onlangs door het Bestuur van het Genootschap genomen besluit om een bijzonderen leerstoel te stichten voor de vergelijkende Psychologie der dieren, de jongste spruit van onze Zoologische Wetenschap. De talrijke vragen, die zich daarbij voordoen, kunnen nauwelijks elders, als in een goed georganiseerden dierentuin bestudeerd worden. Zoo de vraag of het ooit mogelijk zal blijken door een psychoanalytische ontleding der instincten het altijd duistere begrip van instinct geheel uit de dier-psychologie te doen verdwijnen, zooals Georges BoHN dit vermoedt; dan de bekende vragen, hoe de dieren leeren, hoe zij ondervinding opdoen, hoe het met hun herinneringsvermogen staat, om maar enkele punten te noemen. Maar bij dat al is niet te vergeten, dat wij bij ieder dier met een organische en psychische eenheid te doen hebben, wat vooral door de Amerikaansche onderzoekers wel wat te veel schijnt vergeten te worden. Zeer terecht wijst daarom BASTIAN SCHMID op het groote belang van de bestudeering der gezamenlijke vormen van uitdrukking bij onze hooger ontwikkelde dieren in verschillende gemoedstoestanden en omstandigheden, waarbij misschien nog wel het eerst aanknoopingspunten te vinden zijn met onze menschelijke psyche, waarop reeds DaRWIN gewezen heeft.

Evenwel dit alles kan alleen dan goede vruchten afwerpen, wanneer het nieuwe gebouw zoowel der vergelijkende psychologie als der vergelijkende psysiologie wordt opgebouwd op een fundament van kennis der vergelijkende anatomie, gesteund door de ervaringen uit de pathologie opgedaan. Men denke slechts aan het vergelijkend anatomisch hersenonderzoek van MONAKOW, WinKLER, HERRICK, ARIENS KAPPERS, om maar enkelen te noemen, dat voor de vergelijkende psychologie van zooveel belang bleek te zijn; of ook aan de vergelijkend physiologische experimenten van PAWLAV en van zoovele anderen. Hoe dan ook in de naaste toekomst de richting moge zijn, waarin zich de zoologische wetenschap bij voorkeur zal bewegen, in alle gevallen zal de vergelijkende morphologie de grondslag moeten blijven voor alle onderzoekingen en zullen ook onze studenten in de biologie zich in de eerste plaats daarop hebben toe te leggen. Daarom moet dan ook het nieuwe Zoologisch Instituut in hoofdzaak daarop zijn ingesteld, terwijl ik toch ook meen, dat de oude beproefde methode der vergelijkende anatomie en embryologie haar bestaansrecht zal weten te handhaven naast de nieuwere richtingen, die op het oogenblik aan velen meer belangstelling blijken in te boezemen. Ja zien wij zelfs, hoe bij de studie van den bouw der uitgestorven dieren, een wetenschap, die men a priori geneigd zou zijn als een uitsluitend morphologische te beschouwen, meer en meer het streven op den voorgrond komt te trachten die oude fossielen als het ware leven in te blazen en hun bouw te verstaan in verband met hun omgeving, wat wij tegenwoordig in navolging van ABEL met den naam van Palaeobiologie bestempelen.

Moge de arbeid in het nieuwe Zoologisch Instituut het bewijs leveren, dat de werklust en de goede geest, die in het oude laboratorium altijd geheerscht hebben, ook daarheen mede zijn overgegaan, al is het dan ook, dat in de toekomst misschien meer in andere banen zal gewerkt worden en moge blijken, dat ook wij ouderen van dagen niet blind zijn voor de teekenen des tijds, al zal ons eigen werk zich wel blijven bewegen in de oude beproefde werkwijzen. 


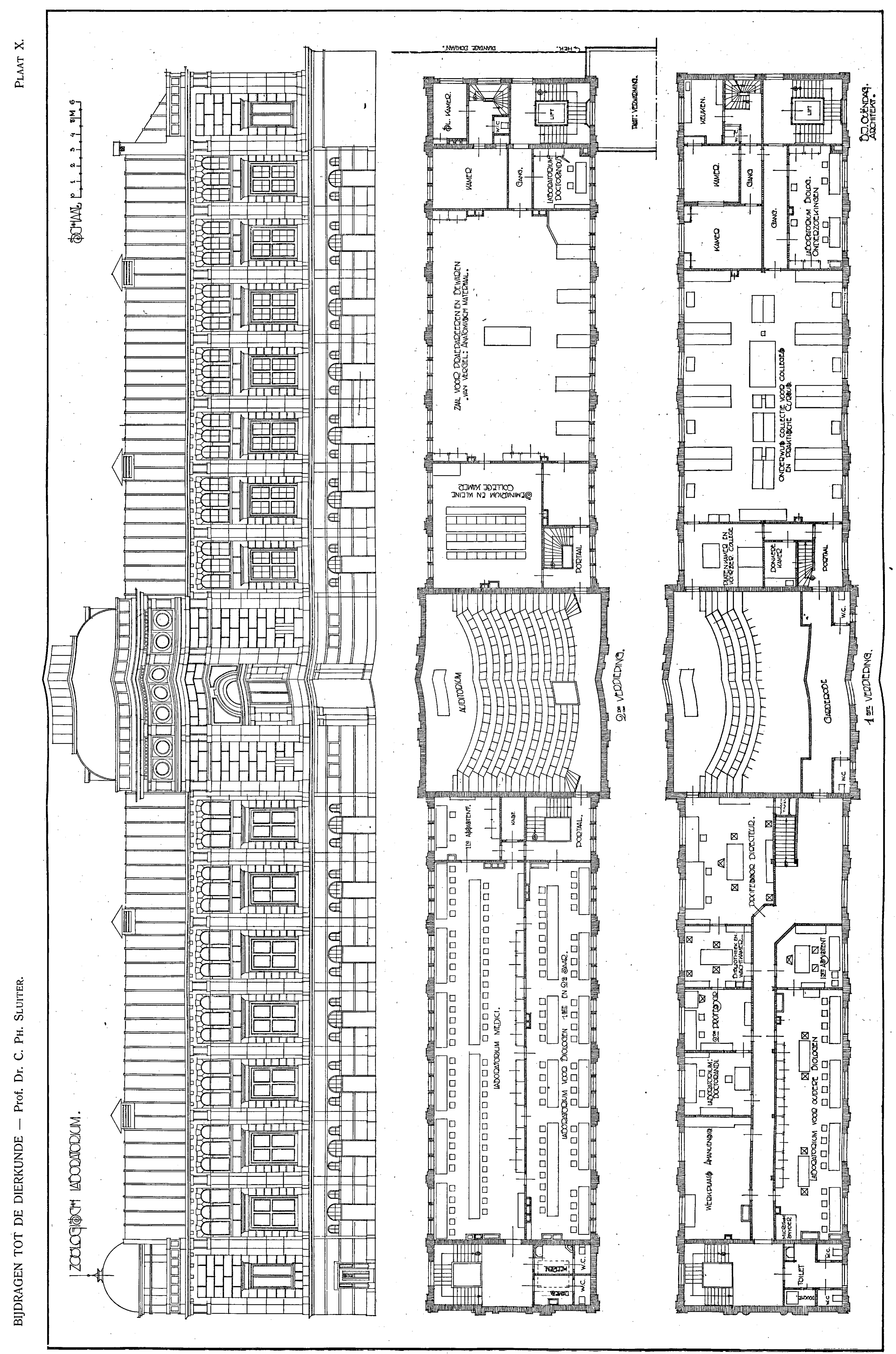

